\title{
Erratum to: Guidelines for the labelling of leucocytes with ${ }^{111}$ In-oxine
}

\section{Manel Roca • Erik F. J. de Vries • Francois Jamar • \\ Ora Israel • Alberto Signore}

Published online: 1 April 2010

(C) Springer-Verlag 2010

Erratum to: Eur J Nucl Med Mol Imaging (2010) 37:835-

841

DOI 10.1007/s00259-009-1993-5

The wrong supplier was named for the Leukokit closed disposable sterile system for WBC separation and labelling. The correct manufacturer of the Leukokit system is GI Pharma (Saluggia, Italy).

The online version of the original article can be found at http://dx.doi. org/10.1007/s00259-009-1993-5.

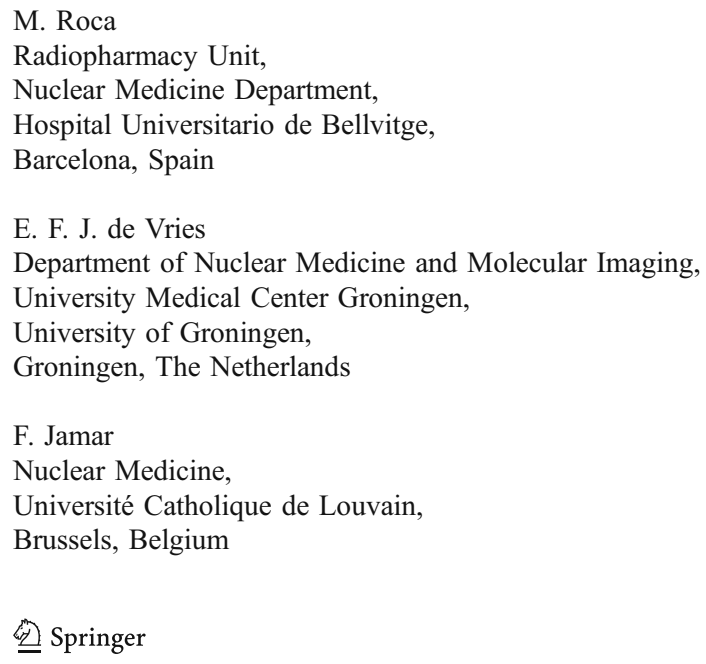

O. Israel

Departments of Nuclear Medicine,

Rambam Health Care Campus,

Haifa, Israel

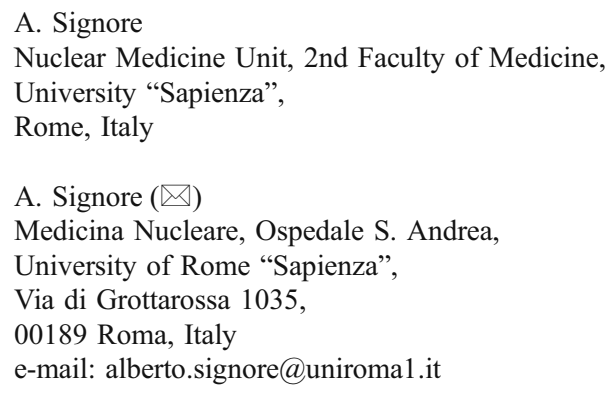

A. Signore

Nuclear Medicine Unit, 2nd Faculty of Medicine, University "Sapienza",

Rome, Italy 